\title{
Rehabilitation Programs for Cystic Fibrosis - View from a CF Center
}

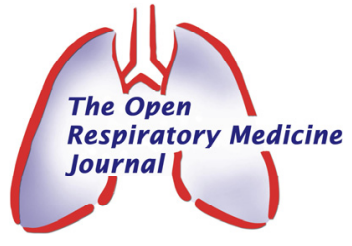

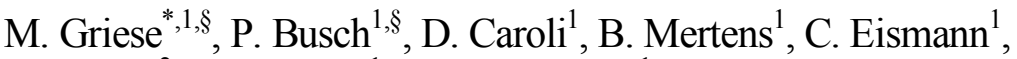 \\ M. Harari ${ }^{2}$, H. Staudter ${ }^{1}$ and M. Kappler ${ }^{1}$
}

${ }^{I}$ Cystic Fibrosis Center, Dr. von Haunersches Kinderspital, University of Munich, Lindwurmstr. 4, D-80337 Munich, Germany

${ }^{2}$ Christiane Herzog Dead Sea CF-Climate Therapy Centre and German Medical Center, Dead Sea, Ein Bokek 86930, Israel

\begin{abstract}
Background: Rehabilitation programs are comprehensive interventions which effectively improve the health status and reduce costs in chronic respiratory illnesses. Because patients with cystic fibrosis have been discouraged to participate for concerns of microbial cross infection, the efficacy of systematic rehabilitation is unknown for this group.

Methods: We retrospectively studied 142 cystic fibrosis patients aged 2-46 years who participated in rehabilitation programs taking place in Germany/Switzerland and in Israel, focusing on changes in lung function and weight.

Results: During 172 stays in 97 patients in Israel and 68 stays in 45 patients rehabilitating in Germany/Switzerland, overall lung function and weight improved. Outcome did not differ between Israel and German/Swiss sites. Interestingly, lung function improved during the initial phase of the stay, whereas weight gain was sustained throughout. The study uncovered gaps in reporting sufficient individual outcome information back to the admitting centre.
\end{abstract}

Conclusions: Rehabilitation programs specified for cystic fibrosis patients need to be assessed prospectively to optimize treatment of this life limiting condition.

Keywords: Cystic fibrosis, rehabilitation, summer camp.

\section{INTRODUCTION}

A recent statement of the American Thoracic Society (ATS) and the European Respiratory Society (ERS) on pulmonary rehabilitation highlights the great progress that has been made in evidence-based support for pulmonary rehabilitation in the management of patients with chronic respiratory disease [1]. Rehabilitation programs are comprehensive interventions which have been shown primarily for individuals with chronic obstructive pulmonary disease (COPD), to reduce dyspnoea, increase exercise performance, improve health-related quality of life (HRQL), and to reduce effectively health care costs [1].

Although it has become clear that patients regardless of the type of chronic respiratory disease, experience a substantial morbidity from secondary impairments, like peripheral muscle, cardiac, nutritional, and psychosocial dysfunction, as well as suboptimal self-management strategies, comparable data are barely available in patients with cystic fibrosis. In fact, in the mentioned ATS/ERS statement this disease entity is mentioned only twice [1]. Thus it is evident that for cystic fibrosis patients up-to-date

*Address correspondence to this author at the Dr. von Haunersches Kinderspital, University of Munich, Lindwurmstraße 4, D-80337 Munich, Germany; Tel: ++49 895160 7871; Fax: ++49 895160 7872;

E-mail: Matthias.griese@med.uni-muenchen.de

${ }^{\S}$ Shared first authorship. evaluated and structured rehabilitations programs have not yet been developed. Reasons for this may include that cystic fibrosis patients only represent a small group of subjects, include a broad age range from infancy to adulthood, and most importantly the bad experiences made previously in socalled summer camps. These were holiday-like rehabilitation efforts for cystic fibrosis patients, which were not infection controlled and cohorted considering pulmonary pathogens. In these camps a significant risk of microbial cross infection between patients was demonstrated [2-8]. Nevertheless, rehabilitation programs in cystic fibrosis have a long standing tradition in some European countries [9-13]. These programs absolutely differ from the so-called summer camps, especially because of taking very carefully into account hygiene aspects, among many other factors. They are perceived as helpful from a patient's perspective, as they appear to improve health status, specific physiotherapeutic and psychosocial skills, and disburden families with small children and single adults. Many physicians share this attitude; the programs are paid by the national state insurance system every 4 years, in exceptional cases depending on individual state of health every 1-2 years.

Unfortunately very little is known on the quality and safety of these programs. For a full positioning of such programs and more importantly for their future development into definite evidence based pulmonary rehabilitation for $\mathrm{CF}$ patients according to state of the art knowledge, a description of the current outcome of these programs is desirable. 
We therefore evaluated the effect of rehabilitation programs at different sites and in an unbiased manner by comparing data on the clinically most important measurements concerning lung function and bodyweight before and after the programs. Additionally, the amount of missing data from rehabilitation site reports was analysed.

\section{MATERIALS AND METHODOLOGY}

We retrospectively studied the rehabilitation related data from all consecutive subjects at our center processed by one single social worker who had participated in the rehabilitation program in Israel during the seasons 1999/2000 to $2003 / 2004$ and the data from all subjects who participated in German/Swiss rehabilitation programs during a similar time period. The patients from the German/Swiss rehabilitation centres were combined to one group, in order to compare the results to the Israel rehabilitation program which took place in a totally different climate during winter time in Germany and Switzerland.

\section{Medical Sites}

\section{The Israel Rehabilitation Site}

The program is located at the Christiane-Herzog-Dead Sea Cystic Fibrosis-Climate Therapy Centre, located in the rehabilitation hotel Lot, Ein Bokek, Israel. The site is located $390 \mathrm{~m}$ below sea level, with humidity of $20-50 \%$, a lack of pollen, and temperatures between maximal $20-23^{\circ} \mathrm{C}$ and minimal $11-14^{\circ} \mathrm{C}$. The program was active during the winter season of Germany and Switzerland and the length of the stay for each patient was 3 weeks.

\section{The German/Swiss Rehabilitation Sites}

The six German speaking rehabilitation sites were the Alpine Kinderklinik Davos, Davos, Switzerland; Klinikum Berchtesgadener Land, Berchtesgaden, Germany; Rehabilitationszentrum Borkum-Klinik Borkum Riff, Borkum, Germany; Fachklinik Satteldüne, Amrum, Germany; KinderRehazentrum Usedom, Usedom, Germany; Nachsorgeklinik Tannheim, Villingen-Schwennigen-Tannheim im Schwarzwald, Germany.

The program was active mainly during the spring to autumn season of Germany and Switzerland, 73\% of the stays were during the warm season (May to August), and the length of the stay for each patient was 3 weeks or longer.

\section{Main Features of the Rehabilitation Programs}

The rehabilitation programs included daily chest physiotherapy for one hour in addition to routine selfphysiotherapy. The maintenance therapy with oral and/or inhaled antibiotics, pancreatic enzyme supplements, vitamins, and bronchodilator inhalations as individually prescribed by each patient's physician, was kept constant. A number of structured outdoor physical activities including various ball games, horse riding, cycling and walking tours, yoga and other self-stabilizing techniques, and social activities were offered for participation. A high caloric food with daily nutritional supplements was reinforced in all subjects. Details on the instrumentation of the different sites are given in Table $\mathbf{1 .}$

All patients were defined according to their microbiological status and grouped into those without Pseudomonas aeruginosa ( $P$. aeruginosa) and with $P$. aeruginosa. Patients with B. cepacia or MRSA were excluded from the regular program. The categorization of the patients was done on the basis of sputum or throat swab examinations from the year before the stay. At least three previous 3 monthly results had to be available and, in addition, a recent swab from within the last 2 months before the stay. Furthermore, all patients were educated in personal hygiene measures along the guidelines for infection control in outpatient cystic fibrosis patients as published previously [14] including disinfection of hands, no close contact to other participants, and strict usage of personal equipment for inhalation. At all sites the appropriate hygiene surface and cleaning procedures were in place. In all programs the patients usually had private rooms; in case of small children these were shared with a family member accompanying them. Patients usually brought their own personal inhalation devices, sterilizing equipment for these, and their medication with them.

\section{Patient Population, Outcome Variables and Comparisons}

Inclusion criteria were the diagnosis of cystic fibrosis by clinical symptoms and a positive sweat test or conclusive molecular genetics and a clinically stable condition. Indications for the medical rehabilitation were of broad nature, though including in all patients an unsatisfying course of weight and/or lung function or dissatisfactory compliance with therapy. Details on the numbers and the baseline characteristics of the patients participating are given in Tables $\mathbf{2}$ and $\mathbf{3}$.

The patients were seen at the rehabilitation centre by a medical doctor and clinical data as bodyweight, height, spirometry, and transcutaneous oxygen saturation were taken at the beginning (Table 3 ) and at the end of the stay ideally. In a subset of patients these data were obtained after one week, in addition daily peak flow measurements and a 6 min walking test on a treadmill was performed at the beginning and the end of these stays. In a first step, differences between the initial measurements taken at the site and the last measurements taken at the site were performed. Therefore only complete (before and after) pairs are considered and the number $\mathrm{N}$ of which is indicated. The changes are indicated as median in the units of the original variable (see Table 3 ) and as absolute numbers of subjects. A change was defined as "better" if the value taken at the end was higher than at the beginning, as "same", when the vales were the same and as "worse", when the values were lower. Comparisons between the before and after changes were made by Wilcoxon test, $\mathrm{P}$ is indicated (Table 4).

In a second step, comparisons between the Israel and the German/Swiss programs were performed. For an optimal comparison, the subjects were carefully matched for age, Pseudomonas state, sex, and baseline values of weight and lung function. As the number of subjects was smaller in the German/Swiss programs, it was attempted to match these to appropriate subjects in the Israel program. For the 68 rehabilitation stays in the German sites, 5 patients could not be matched due to non-documented matching variables and in three patients no fitting matching partner could be identified.

\section{Statistics}

All variables were treated by non-parametric tests; comparisons between two time points were made by 
Table 1. Rehabilitation Sites and Their Instrumentation

\begin{tabular}{|c|c|c|c|c|c|c|c|}
\hline Rehabilitation Site & 1 & 2 & 3 & 4 & 5 & 6 & 7 \\
\hline \multicolumn{8}{|l|}{ Physician Related } \\
\hline Intravenous antibiotic therapy possible & No & Yes & Yes & Yes & Yes & Yes & Yes \\
\hline \multicolumn{8}{|l|}{ Physiotherapy and Sport } \\
\hline Physiotherapy lessons and tutorials under supervision of a physiotherapist & Yes & Yes & Yes & Yes & Yes & Yes & Yes \\
\hline Physiotherapist with accredited CF training & Yes & Yes & Yes & Yes & Yes & Yes & Yes \\
\hline \multicolumn{8}{|l|}{ Nutrition } \\
\hline Analysis of dietary records and nutritional counselling by a nutritionist & Yes & Yes & Yes & Yes & Yes & Yes & Yes \\
\hline Intergroup development and one on one interview with a social worker & No & Yes & Yes & Yes & Yes & Yes & Yes \\
\hline Private lessons with a schoolteacher possible & No & Yes & No & No & Yes & Yes & Yes \\
\hline Monitoring of appointed measures by healthcare workers & Yes & Yes & Yes & Yes & Yes & Yes & Yes \\
\hline \multicolumn{8}{|l|}{ Other } \\
\hline Intensive care in case of acute medical problems possible & Yes & Yes & Yes & Yes & Yes & Yes & Yes \\
\hline Particular climatic condition & Yes & Yes & Yes & Yes & Yes & Yes & No \\
\hline Spatiotemporal segregation according to $P$. aeruginosa status & Yes & Yes & Yes & Yes & Yes & Yes & Yes \\
\hline Infection control measures & Yes & Yes & Yes & Yes & Yes & Yes & Yes \\
\hline
\end{tabular}

Table 2. Overview on Rehabilitation Sites, Number of Patients and Duration of Programs

\begin{tabular}{|c|c|c|c|c|c|}
\hline & Seasons/Sites & $\begin{array}{l}\text { Number of } \\
\text { Stays }\end{array}$ & $\begin{array}{c}\text { Duration of Stays } \\
\text { (Days) }\end{array}$ & $\begin{array}{l}\text { Number of } \\
\text { Patients }\end{array}$ & $\begin{array}{l}\text { Number of Patients Coming for the } \\
\text { First Time to that Site }\end{array}$ \\
\hline \multirow[t]{6}{*}{ Israel } & $1999 / 2000$ & 52 & 21 & 52 & 52 \\
\hline & $2000 / 2001$ & 55 & 21 & 55 & 35 \\
\hline & $2001 / 2002$ & 23 & 21 & 23 & 4 \\
\hline & $2002 / 2003$ & 14 & 21 & 14 & 4 \\
\hline & $2003 / 2004$ & 28 & 21 & 28 & 2 \\
\hline & Sum or mean & 172 & 21 & 172 & 97 \\
\hline \multirow[t]{7}{*}{ Germany, Switzerland } & Site 2, 1995-1998 & 6 & 30.3 & 5 & 5 \\
\hline & Site 3, 2000-2004 & 5 & 28.8 & 5 & 4 \\
\hline & Site 4, 1998-2004 & 3 & 25.3 & 3 & 2 \\
\hline & Site 5, 1994-2005 & 17 & 38 & 10 & 10 \\
\hline & Site 6, 1997-2004 & 28 & 28 & 16 & 14 \\
\hline & Site $7,1999-2005$ & 9 & 28 & 6 & 4 \\
\hline & Sum or mean & 68 & 30.5 & 45 & 39 \\
\hline
\end{tabular}


Wilcoxon matched pairs, in case of three, Friedman Test followed by Dunn's post hoc test. Two unpaired groups were compared by Mann-Whitney Test, more by Kruskal-Wallis ANOVA, followed by Dunn's post-hoc test. A two-sided $p<$ 0.05 was considered significant. Summary data are given as medians with range or interquartile range.

\section{Ethics Approval}

The retrospective chart review of the results from the rehabilitation centers was performed anonymised. The use of all data obtained was approved by the local institutional review board for human studies of the University of Munich.

\section{RESULTS}

\section{Variable but on Average High Percentage of Missing Data in Reports from Rehabilitation Sites}

From all 142 different subjects and the total number of 240 different rehabilitation stays noted in our files to have been sent to rehabilitation programs, records were retrieved. These were systematically analyzed for the pre-defined key variables listed in Table 3. Whereas lung function values frequently were not reported by the sites in Germany/ Switzerland, weight was less frequently reported from the Israel site. Values for peak flow and a 6 min walk test were solely reported in a small subgroup of patients for certain seasons.

\section{Improvement of Lung Function and Weight with the Rehabilitation Intervention}

First we analyzed all cystic fibrosis patients staying at the Israel site and those at the German and Swiss sites separately. Whereas the baseline data for age, lung function, weight and Pseudomonas status of the two groups of patients were very similar, the number of missing values for some variables was different between the groups (Table 3). Overall lung function values and weight improved (Table 4). At the Israel site FVC and oxygen saturation improved significantly, whereas at the German sites $\mathrm{FEV}_{1}$ did. In order to better describe individual outcomes, the numbers of patients improving, getting worse or remaining unchanged were assessed (Table 4). Whereas a substantial fraction of subjects deteriorated with respect to lung function, weight clearly improved in the majority of patients, both in the German and Israel sites (Table 4). Taken together, rehabilitation programs at both sites led to improved lung function and weight.

\section{Early Improvement of Lung Function and Sustained Gain of Weight}

The variable duration of the stays in the German/Swiss rehabilitation sites could be used to assess the effect of length of stay on the outcome of rehabilitation. In addition, this aspect was addressed in 61 patients in the seasons 2000/2001, 2001/2002, 2002/2003 and 2003/2004 of the Israel rehabilitation programs. During these stays additional measurements at the end of the first week (on average on day 9.2) of the 3-week stay were performed.

In this subgroup of 61 patients significant changes of paired lung function $\left(\mathrm{FEV}_{1}, \mathrm{FVC}\right.$, MEF25-75, oxygensaturation), weight and BMI were observed. Whereas lung function clearly improved during the first week, weight improved continuously over the whole rehabilitation period (Fig. 1). This observation is in agreement with the observation that the gain of weight, but not the improvement of $\mathrm{FEV}_{1}$ was proportional with the duration of the rehabilitation programs (Fig. 2).

Table 3. Baseline Characteristics of the Cystic Fibrosis Patients Included

\begin{tabular}{|c|c|c|c|c|c|c|c|c|c|c|c|c|}
\hline & $\begin{array}{l}\mathbf{N} \\
\mathbf{n}^{*}\end{array}$ & $\begin{array}{c}\text { Age } \\
(y)\end{array}$ & $\begin{array}{c}\text { Male } \\
(\%)\end{array}$ & $\begin{array}{c}\text { P ae.§ } \\
\text { Pos } \\
(\%)\end{array}$ & $\begin{array}{c}\text { FEV } \\
(\% \\
\text { pred) }\end{array}$ & $\begin{array}{c}\text { FVC } \\
(\% \\
\text { pred) }\end{array}$ & $\begin{array}{c}\mathbf{M E F}_{25-75} \\
(\% \\
\text { pred) }\end{array}$ & $\begin{array}{c}\text { Oxygen- } \\
\text { Saturation } \\
(\%)\end{array}$ & $\begin{array}{l}\text { Weight } \\
\text { (kg) }\end{array}$ & $\underset{\left(\mathrm{kg} / \mathrm{m}^{2}\right)}{\mathrm{BMI}}$ & $\begin{array}{c}\text { PEF } \\
* * * * \\
(1 / \mathrm{min})\end{array}$ & $\begin{array}{c}\text { 6MWT } \\
* * * * * \\
\text { (m) }\end{array}$ \\
\hline Israel & $\begin{array}{c}172 \\
97\end{array}$ & $\begin{array}{l}16.5 \\
(2- \\
46)\end{array}$ & 48 & 69 & $\begin{array}{c}63 \\
(15-122)\end{array}$ & $\begin{array}{c}82 \\
(15-152)\end{array}$ & $\begin{array}{c}31 \\
(4-135)\end{array}$ & $\begin{array}{c}97 \\
(78-99)\end{array}$ & $\begin{array}{c}47 \\
(13-82)\end{array}$ & $\begin{array}{c}18 \\
(13-27)\end{array}$ & $\begin{array}{c}390 \\
(210- \\
500)\end{array}$ & $\begin{array}{c}400 \\
(120-590)\end{array}$ \\
\hline $\begin{array}{l}\text { Data missing** } \\
(\% ; \mathrm{n} / \mathrm{N})\end{array}$ & & 0 & 0 & 0 & $\begin{array}{c}24 \% \\
(42 / 172)\end{array}$ & $\begin{array}{c}24 \% \\
(42 / 172)\end{array}$ & $\begin{array}{c}24 \% \\
(42 / 172)\end{array}$ & $\begin{array}{c}17 \% \\
(29 / 172)\end{array}$ & $\begin{array}{c}24 \% \\
(41 / 172)\end{array}$ & $\begin{array}{c}33 \% \\
(57 / 172)\end{array}$ & $\begin{array}{c}4 \% \\
(1 / 23)\end{array}$ & $\begin{array}{c}59 \% \\
(30 / 51)\end{array}$ \\
\hline $\begin{array}{l}\text { Germany/ } \\
\text { Switzerland }\end{array}$ & $\begin{array}{l}68 \\
45\end{array}$ & $\begin{array}{c}14.0 \\
(3- \\
33)\end{array}$ & 60 & 60 & $\begin{array}{c}63 \\
(27-110)\end{array}$ & $\begin{array}{c}73.6 \\
(4-106)\end{array}$ & $\begin{array}{c}30.5 \\
(12-49)\end{array}$ & $\begin{array}{c}\text { Not } \\
\text { reported }\end{array}$ & $\begin{array}{c}41.3 \\
(14-78)\end{array}$ & $\begin{array}{c}\text { Not } \\
\text { reported }\end{array}$ & $\begin{array}{c}\text { Not } \\
\text { reported }\end{array}$ & $\begin{array}{c}\text { Not } \\
\text { reported }\end{array}$ \\
\hline $\begin{array}{l}\text { Data missing** } \\
(\% ; n / N)\end{array}$ & & $\begin{array}{c}4 \% \\
(3 / 68)\end{array}$ & 0 & $\begin{array}{c}4 \% \\
(3 / 68)\end{array}$ & $\begin{array}{c}54 \% \\
(37 / 68)\end{array}$ & $\begin{array}{c}82 \% \\
(56 / 68)\end{array}$ & $\begin{array}{c}94 \% \\
(64 / 68)\end{array}$ & & $\begin{array}{c}10 \% \\
(7 / 68)\end{array}$ & & & \\
\hline $\begin{array}{l}\text { Comparison of } \\
\text { missing data from } \\
\text { sites Israel and } \\
\text { Germany/Switzerland } \\
\text { \# }\end{array}$ & & ns & & ns & $<0.0001$ & $<0.0001$ & $<0.0001$ & nd & 0.018 & nd & nd & nd \\
\hline
\end{tabular}

$\mathrm{FEV}_{1}$ : Forced Expiratory Volume in 1 Second; FVC: forced expiratory vital capacity, $\mathrm{MEF}_{25-75}$ : Middle Expiratory Flow between $25 \%$ and $75 \%$ of FVC, BMI: Body Mass Index, PEF: Peak Expiratory Flow rate, 6MWT: 6-minute walk test.

* $\mathrm{N}$ indicates the number of stays included and $\mathrm{n}$ the number of subjects. Of the 97 patients included in the Israel program, 38 participated several times (14 patients 2 times, 12 patients 3 times, 11 patients 4 times and 1 patient 5 times). Of the 45 patients included in the German speaking site program, 12 participated several times ( 8 patients 2 times, 1 patient each $3,4,5$, and 7 times). $§ P$. aeruginosa status at start of a stay.

** Given is the percentage of measurements expected (no correction is made for lung function measurements in children of young age) and in brackets the number of missing information on stays in relation to the total number of stays included.

*** obtained in season 2001/2002 in total of 23 subjects. **** obtained in seasons 2001/2002, 2003/2004, in total of 51 subjects.

\# Frequencies were compared by Fisher's exact test.

Data are median (min-max) 
Table 4. Differences in Variables Before and After Rehabilitation in All Cystic Fibrosis Patients Included for the Israel, Dead Sea Area (172 Stays) and the German and Swiss Sites (68 Stays)

\begin{tabular}{|c|c|c|c|c|c|c|c|c|c|c|c|c|}
\hline \multirow{2}{*}{ Change in } & \multicolumn{6}{|c|}{ Israel } & \multicolumn{6}{|c|}{ Germany, Switzerland } \\
\hline & $\begin{array}{l}\text { Absolute } \\
\text { Difference }\end{array}$ & $\mathbf{P}$ & $\begin{array}{l}\text { N of } \\
\text { Pairs }\end{array}$ & $\begin{array}{c}\mathbf{N} \\
\text { Better }\end{array}$ & $\begin{array}{c}\mathrm{N} \\
\text { Same }\end{array}$ & $\begin{array}{c}\mathrm{N} \\
\text { Worse }\end{array}$ & $\begin{array}{c}\text { Absolute } \\
\text { Difference }\end{array}$ & $\mathbf{P}$ & $\begin{array}{l}\text { N of } \\
\text { Pairs }\end{array}$ & $\begin{array}{c}\mathbf{N} \\
\text { Better }\end{array}$ & $\begin{array}{c}\mathbf{N} \\
\text { Same }\end{array}$ & $\begin{array}{c}\mathbf{N} \\
\text { Worse }\end{array}$ \\
\hline $\mathrm{FEV}_{1}(\%$ pred $)$ & $1.0(-3,5)$ & 0.10 & 130 & 71 & 12 & 47 & $3.0(-0.5,9.5)$ & 0.035 & 30 & 22 & 2 & 6 \\
\hline $\mathrm{FVC}(\%$ pred $)$ & $4.0(-2,11)$ & $<0.01$ & 130 & 86 & 7 & 37 & $6.8(-2.9,16)$ & 0.11 & 12 & 9 & 0 & 3 \\
\hline MEF25-75 (\% pred) & $0.5(-3,5)$ & 0.23 & 130 & 65 & 15 & 50 & $0.0(-10,2.5)$ & 1.25 & 4 & 2 & 1 & 1 \\
\hline Oxygen-saturation (\%) & $1(0,1)$ & $<0.01$ & 143 & 66 & 45 & 32 & Not given & & & & & \\
\hline Weight (kg) & $1.0(0.2,1.6)$ & $<0.01$ & 131 & 106 & 6 & 19 & $1.2(0.3,2.1)$ & $<0.01$ & 60 & 52 & 1 & 7 \\
\hline BMI (kg/m2) & $0.4(0.1,0.7)$ & $<0.01$ & 114 & 92 & 6 & 16 & Not given & & & & & \\
\hline
\end{tabular}
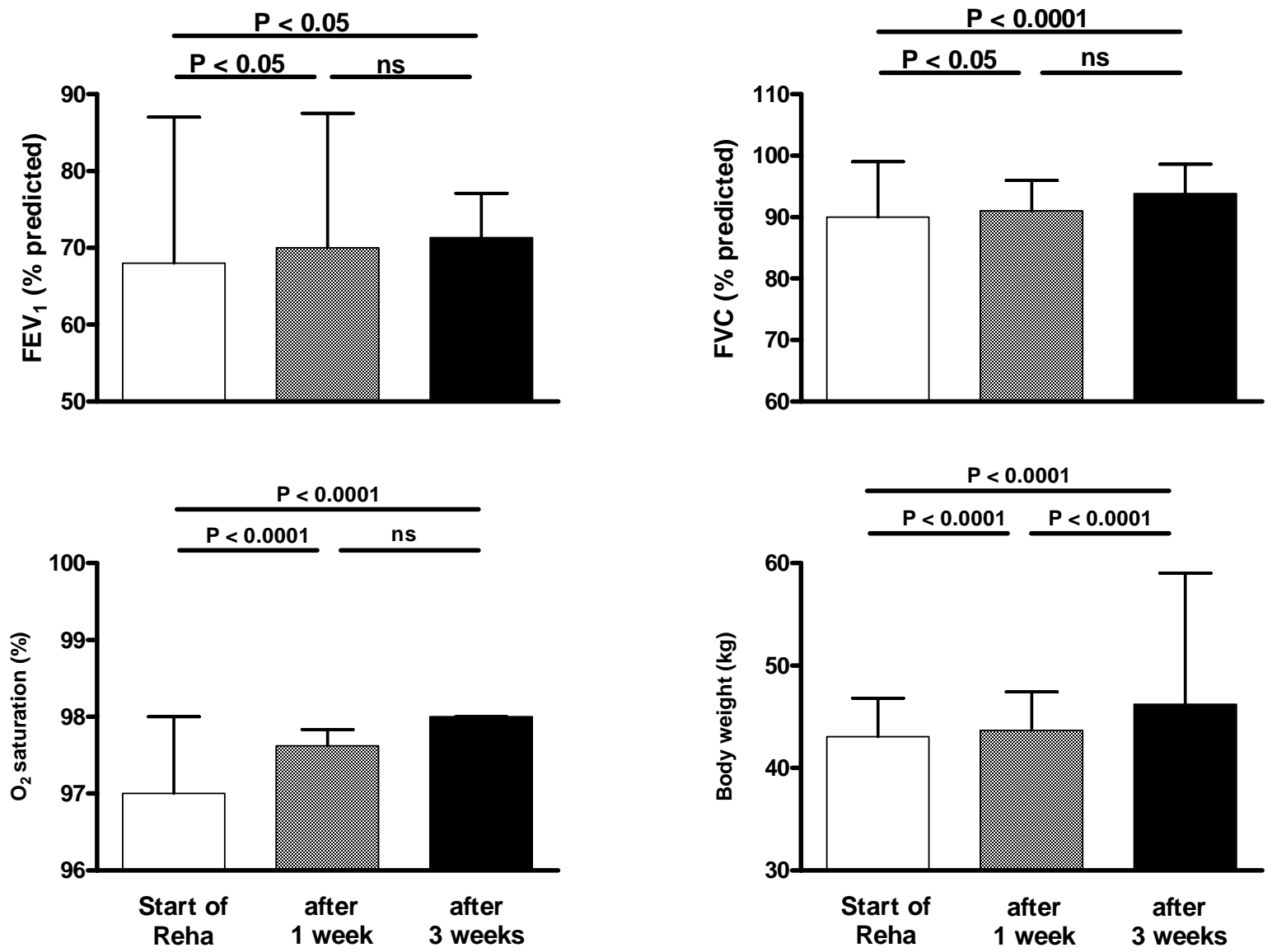

Fig. (1). Medians and interquartile range of $\mathrm{FEV}_{1}$, FVC, oxygen-saturation and body weight during the seasons 2000/2001, 2001/2002, $2002 / 2003$ and 2003/2004 of the Israel rehabilitation programs. Additional measurements at the end of the first week (on average on day 9.2 ) of the 3-week stay were performed prospectively to determine when potential effects of the intervention become evident. The paired data from the 3 time points were compared by Friedman-ANOVA, followed by Dunn`s multiple comparison test.

\section{No Differences in the Extent of the Rehabilitation Effects Between Israel and German/Swiss Sites}

A direct overall comparison of the Israel and German rehabilitation programs did not show significant differences of the basal data and of the changes associated with the rehabilitation with respect of age, sex, percentage of Pseudomonas positive subjects, weight, and lung function. It must be noted however that the time of the year when the programs took place and their durations were different, as were the numbers of participants (Tables $\mathbf{2}$ and $\mathbf{3}$ ).

To circumvent some of these problems an additional comparison was made after very careful matching of subjects for age, Pseudomonas state, sex, and baseline values of weight and lung function. Again, no differences for the improvement of lung function (Fig. 3a, b) and weight were observed (Fig. 3c). The figure illustrates the wide range of individual changes observed. 

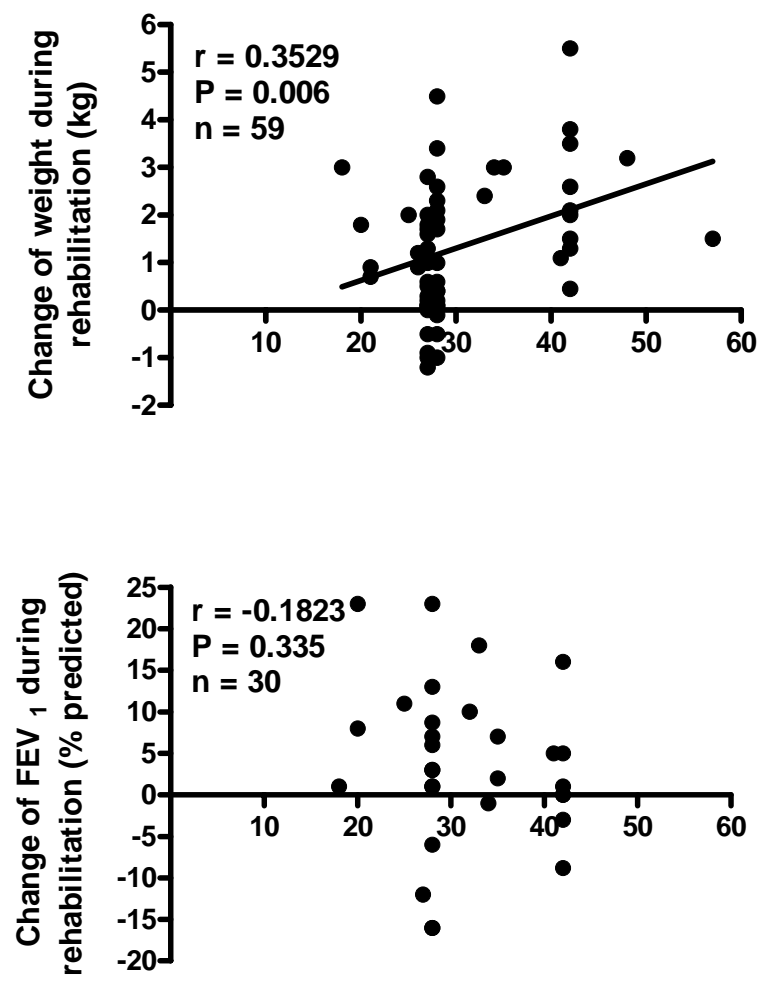

Duration of rehabilitation (d)

Fig. (2). Spearman correlations between the duration of the rehabilitation programs in Germany/Switzerland and the changes in weight and lung function $\left(\mathrm{FEV}_{1}\right)$. The Israel groups were not included as their stay was always fixed to 3 weeks.

\section{DISCUSSION}

The overall completeness of the reports on quantitative key outcomes was clearly low in all rehabilitation programs investigated. Based on the data retrieved, both the Israel and the German/Swiss rehabilitation programs significantly improved overall lung function and weight of patients with cystic fibrosis of all age groups. At the Israel site FVC and oxygen-saturation improved, whereas at the German sites $\mathrm{FEV}_{1}$ did. While lung function improved early on and then remained stable, the gain of body weight was sustained and proportional to the length of the stay. Inter-individual responses were much more pronounced than variability within subjects. There were no differences in the extent of the rehabilitation effects at Israel and German/Swiss sites, as shown by matched comparisons.

This is to our knowledge the largest systematic analysis of rehabilitation programs in patients with cystic fibrosis published so far. One of the strengths of this study is that it included all patients of a predefined group of subjects from our centre that participated in the mentioned rehabilitation activities. Thus a selection bias was avoided and with the "intention to treat analysis" approach, we were able to obtain a "real life" assessment of the outcome. Since complete and unbiased up-to-date evaluation by the rehabilitation program providers are not published in an accessible way, we decided to do this analysis from the perspective of a site submitting patients, accepting potential disadvantages of this approach.
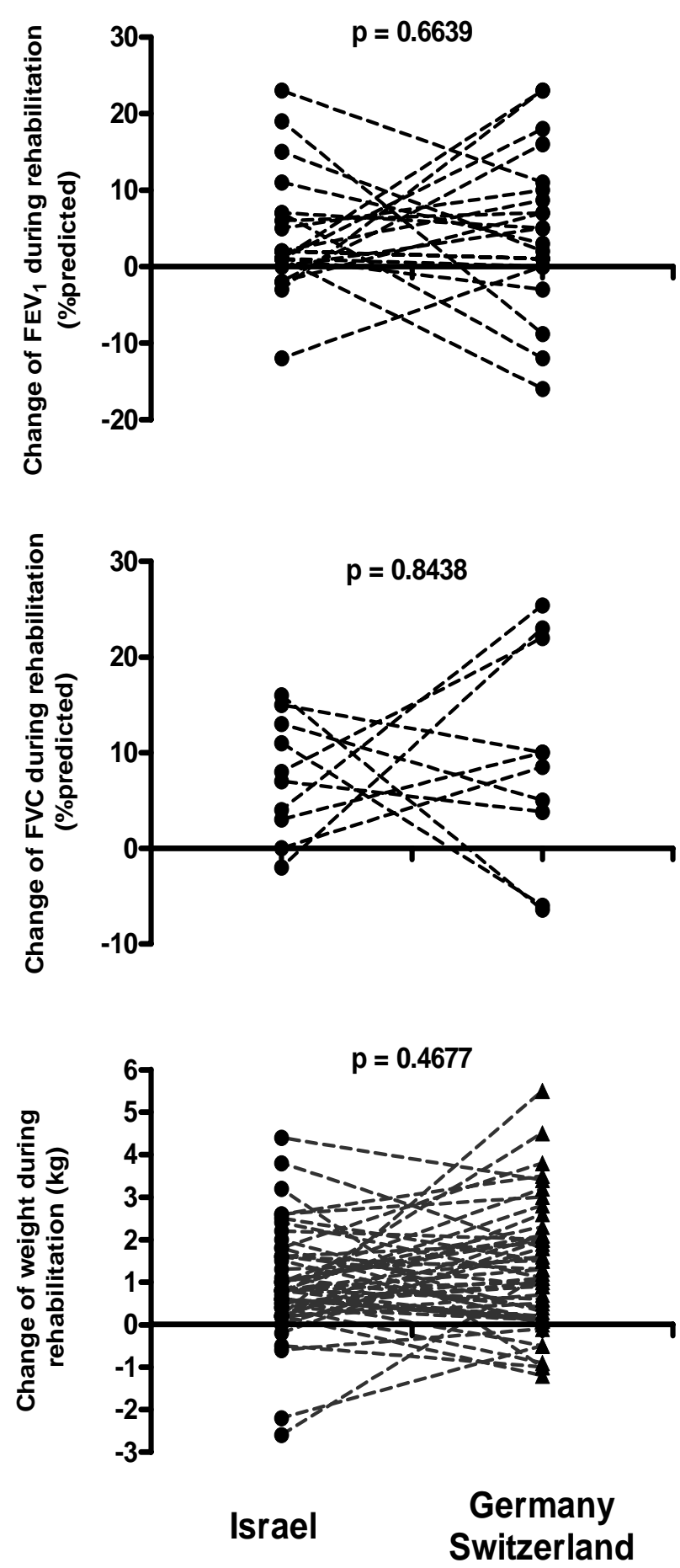

Fig. (3). Changes of lung function and weight during rehabilitation in a matched group of patients of the Israel and German/Swiss rehabilitation program. The subjects from the German/Swiss sites were carefully matched by age, Pseudomonas state, sex, and baseline values of weight and lung function to fitting partners from the Israel site. Dotted lines connect matched subjects. Note that these are different subjects matched by chance and not the same individuals staying at both sites. Differences were assessed by Wilcoxon-Test and $p$ values are indicated. 
First, the submitting centre did not always receive the appropriate medicinal and psychosocial information necessary to judge on the success or failure for a particular patient, including missing data for key variables before and after the program, reports on exacerbations during a stay, data on other untoward events or on psychosocial problems. Second, the precise nature and frequency of interventions performed by the patients often remained unclear. We can only infer from the procedures stated in the program description provided by the rehabilitation centres what might be offered to the patient. Third, the results we present here, only concern cystic fibrosis patients from our centre and results of patients from other submitting sites are unknown. However, the major advantage of this approach is an overview on the outcome of the current rehabilitation programs currently utilized in Germany, Switzerland and Israel. Extra attention was put on the quality of the reports received from the rehabilitation sites, because values on key measurements often were missing in these reports.

The study clearly demonstrated that one of the apprehensions made before the study was true, i.e. that the quality of many of the reports received from the rehabilitation sites was inappropriate; clearly it cannot be tolerated that in up to more than $50 \%$ of the critical variables, e.g. lung function, describing the impact of an individual rehabilitation, are not given in the reports of some rehabilitation sites. We interpret this result as one strength of this study to clearly visualize missing data for the first time in a study on rehabilitation programs in cystic fibrosis, although of course the missing data somewhat weaken the value of the nevertheless large data set. For the future therefore it will be essential to improve data reporting on the part of rehabilitation sites.

Having these limitations in mind, some inferences can be drawn from this retrospective analysis. We show for two key indicators of health in cystic fibrosis patients, both, lung function and weight, an overall significant improvement by these rehabilitation programs. We determined the extent and variability of changes that can be expected and also the fraction of subjects not responding favorably. Of interest there was a steady time dependent improvement in body weight, which was demonstrated independently in two cohorts. Weight is an indicator not only of overall fitness but also an independent risk factor for survival in cystic fibrosis patients [15] similarly as $\mathrm{FEV}_{1}$ [16]. Due to the nature of our study and mainly because of the large amount of missing data reported, we also cannot analyze which intervention(s) were performed in which individual patients and which were responsible for the changes observed. Overall the results clearly demonstrate that rehabilitation programs as assessed here may objectively be helpful in a substantial fraction of cystic fibrosis patients and that they have the potential to be further developed into high quality and evidence based programs, which must be warranted by prospective evaluation.

Previous small cohort studies have already assessed the physiological impact of rehabilitation on nutritional status [17] and, at the Israeli site, on exercise capacity, which improved [10], and on pulmonary function and weight gain during and up to 3 months after the three week rehabilitation [18]. The results were in concordance with our findings.
Unfortunately the latter study also had a retrospective design and the completeness of the sample is not known. Problems with selection bias must also be considered in the study on the impact of the rehabilitation program on quality of life indices [11]. In that study an unknown number of patients participating in rehabilitation programs at various sites over undetermined time periods were combined. Interestingly, the quality of life improved for a sustained period of at least two months after the end of the intervention [11]. A study of the site in Davos, Switzerland, which was also included in our study, reporting on 13 Israeli patients with cystic fibrosis, did not find improvement of lung function; however exercise tolerance and weight improved significantly [12]. The authors of the latter study argued for a reinstitution of rehabilitation activities for patients with cystic fibrosis, if special care is taken to prevent cross-infection.

The hygiene aspect is the key for any future development of up-to-date rehabilitation programs in cystic fibrosis. Our study did not target this issue. We did not systematically investigate our patients directly before and after a stay; however patients were only sent to those rehabilitation sites who were sensitized for the hygiene issue as demonstrated by cohorting all their patients on a time and space basis according to their microbiological status and enforcing hygiene rules in personal contact and inhalation equipment (see Table 1). As changes in the microbiological status of a patient were barely included in the reports from the rehabilitation sites, we could not assess this outcome. Although we believe that it is the responsibility of the rehabilitation site to demonstrate lack of transmission, we have recently started to also closely monitor our patients before and after rehabilitation, but in the future evaluation of respiratory pathogens by clonality is required to really assess the cross-infection risk. In the so called summer camps, where patients were encouraged to have close psychosocial contacts and where no structural measures for hygiene were implemented or controlled [3-6], but also in rehabilitation programs when the appropriate measures were not undertaken to prevent clonal spread of cystic fibrosis bacteria $[19,20]$, person to person transmission of bacteria have been demonstrated. Therefore unequivocally the rehabilitation sites have to demonstrate that they are safe from a hygiene aspect. Small cohorts have suggested if the appropriate hygienic precautions are introduced, transmission can be prevented $[9,21]$. In particular, lack of transmission has recently been demonstrated for older cohorts at the Israel site [9].

\section{CONCLUSION}

In patients with many severe chronic pulmonary diseases other than cystic fibrosis, rehabilitation programs in the Western world have successfully improved key outcome variables including lung function, exercise performance and health-related quality of life [1]. From our study and in agreement with other studies mentioned, we can conclude that such goals might also be achieved for patients with cystic fibrosis. If the rehabilitation programs are run for patients with cystic fibrosis at a maximum level of hygienic precautions to prevent cross-infections [22], together with individual improvements of health, the overall health care costs might be reduced. However, it is necessary in the short term, to improve the quality of the reports received from the 
rehabilitation sites and to receive non-biased and standardized assessments of acknowledged outcomes from all subjects. This will help to identify patients who do not profit from the program and target efforts to specifically address their needs. In the long term and with the correct designs implemented it will either be possible to demonstrate safety and efficacy of the programs, or to conclude that this goal cannot be achieved by current programs which must then be stopped and replaced by improved rehabilitation efforts for cystic fibrosis patients. All this is the principal responsibility of the rehabilitation sites. On the one hand the support coming from the insurance companies who pay for the programs is appreciated; on the other hand, these companies should be encouraged to help to further improve the standards to be set for a successful rehabilitation.

\section{ACKNOWLEDGEMENTS}

The paper contains parts of the doctoral thesis of $\mathrm{P}$. Busch. We thank the patients and their families for their cooperation.

\section{CONFLICT OF INTEREST STATEMENT}

All authors disclose any financial and personal relationships with other people or organisations that could inappropriately influence (bias) their work.

\section{REFERENCES}

[1] Nici L, Donner C, Wouters E, et al. American thoracic society/European respiratory society statement on pulmonary rehabilitation. Am J Respir Crit Care Med 2006; 173(12): 1390413.

[2] Brimicombe RW, Dijkshoorn L, van der Reijden TJK, et al. Transmission of Pseudomonas aeruginosa in children with cystic fibrosis attending summer camps in The Netherlands. J Cyst Fibros 2008; 7(1): 30-6.

[3] Centers for Disease Control and Prevention (CDC). Pseudomonas cepacia at summer camps for persons with cystic fibrosis. MMWR Morb Mortal Wkly Rep 1993; 42: 456-9.

[4] Hoogkampkorstanje JAA, Meis JFGM, Kissing J, Vanderlaag J, Melchers WJG. Risk of cross-colonization and infection by Pseudomonas-aeruginosa in a holiday camp for cystic-fibrosis patients. J Clin Microbiol 1995; 33(3): 572-5.

[5] Ojeniyi B, Frederiksen B, Hoiby N. Pseudomonas aeruginosa cross-infection among patients with cystic fibrosis during a winter camp. Pediatr Pulmonol 2000; 29(3): 177-81.

[6] Hunfeld KP, Schmidt C, Krackhardt B, et al. Risk of Pseudomonas aeruginosa cross-colonisation in patients with cystic fibrosis within a holiday camp - a molecular-epidemiological study. Wien Klin Wochenschr 2000; 112(7): 329-33.

[7] Govan JRW, Brown PH, Maddison J, et al. Evidence for transmission of pseudomonas-cepacia by social contact in cysticfibrosis. Lancet 1993; 342(8862): 15-9.

[8] Pegues DA, Carson LA, Tablan OC, et al. Acquisition of Pseudomonas-cepacia at summer camps for patients with cysticfibrosis. J Pediatr 1994; 124(5): 694-702.

[9] Greenberg D, Yagupsky P, Peled N, Goldbart A, Porat N, Tal A Lack of evidence of transmission of Pseudomonas aeruginosa among cystic fibrosis patients attending health camps at the Dead Sea, Israel. Isr Med Assoc J 2004; 6(9): 531-4.

[10] Falk B, Nini A, Zigel L, et al. Effect of low altitude at the dead sea on exercise capacity and cardiopulmonary response to exercise in cystic fibrosis patients with moderate to severe lung disease. Pediatr Pulmonol 2006; 41(3): 234-41.

[11] Schmitz TG, Goldbeck L. The effect of inpatient rehabilitation programmes on quality of life in patients with cystic fibrosis: a multi-center study. Health Qual Life Outcomes 2006; 4: 8.

[12] Blau H, Mussaffi-Georgy H, Fink G, et al. Effects of an intensive 4-week summer camp on cystic fibrosis - Pulmonary function, exercise tolerance, and nutrition. Chest 2002; 121(4): 1117-22.

[13] Nikolaizik WH, Simon HU, Iseli P, Blaser K, Schoni MH. Effect of 3 weeks' rehabilitation on neutrophil surface antigens and lung function in cystic fibrosis. Eur Respir J 2000; 15(5): 942-8.

[14] Schewe D, Kappler M, Griese M. Instructions for infection control in outpatient care of patients with cystic fibrosis. Eur J Med Res 2005; 10(8): 345-51.

[15] Sharma R, Florea V, Bolger A, et al. Wasting as an independent predictor of mortality in patients with cystic fibrosis. Thorax 2001; 56: 746-50.

[16] Courtney J, Bradley J, Maccaughan J, et al. Predictors of mortality in adults with cystic fibrosis. Ped Pulmonol 2007; 42: 525-32.

[17] Rubin BK, Geiger DW. Pulmonary-function, nutrition, and selfconcept in cystic-fibrosis summer campers. Chest 1991; 100(3): 649-54.

[18] Goldbart AD, Cohen AD, Weitzman D, Tal A. Effects of rehabilitation winter camps at the dead sea an European cystic fibrosis patients. Isr Med Assoc J 2007; 9(11): 806-9.

[19] Van Daele S, Verhelst R, Claeys G, et al. Shared genotypes of achromobacter xylosoxidans strains isolated from patients at a cystic fibrosis rehabilitation center. J Clin Microbiol 2005; 43(6): 2998-3002.

[20] Van Daele SG, Franckx H, Verhelst R, et al. Epidemiology of Pseudomonas aeruginosa in a cystic fibrosis rehabilitation centre. Eur Respir J 2005; 25(3): 474-81.

[21] Tummler B, Koopmann U, Grothues D, Weissbrodt H, Steinkamp G, Vonderhardt H. Nosocomial acquisition of Pseudomonasaeruginosa by cystic-fibrosis patients. J Clin Microbiol 1991; 29(6): 1265-7.

[22] Döring G, Hoiby N. Consensus Study Group. Early intervention and prevention of lung disease in cystic fibrosis: a European consensus. J Cyst Fibros 2004; 3(2): 67-91. 